\title{
A Delegação do Porto da SPQ (1978-2017)
}

Após um longo período de inatividade, a SPQ foi reorganizada e dinamizada graças aos esforços de uma Comissão Instaladora que integrava colegas do IST e da FCUL, eleita em Assembleia Geral em 1975. Em 1977, a SPQ foi dotada de uma sede própria em Lisboa (partilhada com as Sociedades de Física e de Matemática), e foi iniciada a publicação de um Boletim Informativo, distribuído gratuitamente a todos os sócios. Tomaram-se medidas para regularizar a publicação da Revista Portuguesa de Química, e lançaram-se as bases para a sustentabilidade financeira das atividades da SPQ, assente na realização de eventos com interesse para os associados, nomeadamente reuniões científicas e de divulgação da Química [Boletim n. ${ }^{\circ}$ 1, junho 1977]. Em janeiro de 1978 realizou-se em Lisboa, com grande sucesso, o 1. ${ }^{\circ}$ Encontro Nacional de Química. Nessa altura foram também eleitos os corpos gerentes nacionais, nomeadamente o Secretário-Geral, Alberto Romão Dias [Boletim n. ${ }^{\circ}$ 3, março 1978]. Posteriormente realizaram-se as eleições para as três Delegações da SPQ: Norte (com sede no Porto), Centro (com sede em Coimbra) e Sul (com sede em Lisboa). Finalmente, em maio foram eleitos o Presidente (Maria Alzira Almoster Ferreira) e Vice-Presidente (M.A.V. Ribeiro da Silva), ficando assim completa a equipa dirigente da SPQ para o triénio 1978-1981 [Boletim n. ${ }^{\circ}$ 4, junho 1978].

O primeiro Presidente da Delegação Norte foi o colega Manuel A. V. Ribeiro da Silva, que se manteve no cargo até 1990, ano em que foi substituído por José Luís Figueiredo [Boletim n. ${ }^{\circ}$ 40, junho 1990]. No período 1978-1990 fizeram ainda parte da Direção da Delegação Norte os colegas: José Alberto Ferreira Gomes, José Luís Costa Lima, Duarte Costa Pereira e Baltazar Romão de Castro, que ocuparam alternadamente os cargos de Secretário e Vogal. De referir que M.A.V. Ribeiro da Silva foi também Presidente da SPQ no período 1986-1989, e Editor da Revista Portuguesa de Química (juntamente com António Varandas) desde 1984 até 1992.

As Delegações tinham bastante autonomia, inclusivamente financeira, uma vez que recebiam as quotas dos seus afiliados. Uma das primeiras tarefas da Delegação Norte foi a organização do $2 .^{\circ}$ Encontro, que decorreu na Faculdade de Economia da Universidade do Porto de 3 a 5 de janeiro de 1979. Com cerca de 700 participantes, 6 Conferências Plenárias e 287 comunicações (um acréscimo de $87 \%$ relativamente ao ano anterior), o $2 .^{\circ}$ Encontro constituiu uma inegável confirmação da vitalidade da SPQ [Boletim n. ${ }^{\circ}$ 1, Série II, julho 1979].

Os Encontros tinham então uma periodicidade anual, e eram organizados rotativamente pelas três Delegações. Assim a Delegação Norte organizou também o 5. ${ }^{\circ}$ Encontro (1982, no Porto), o 8. ${ }^{\circ}\left(1985\right.$, em Braga) e o $10 .^{\circ}$ (realizado no Porto em 1987, para coincidir com o $75 .^{\circ}$ aniversário da SPQ).

O 5. ${ }^{\circ}$ Encontro decorreu também na Faculdade de Economia da UP, de 29 de março a 3 de abril de 1982. Estive- ram presentes 950 participantes, incluindo 278 espanhóis. Houve 5 lições plenárias, 6 comunicações convidadas e 261 comunicações em painel [Boletim n. ${ }^{\circ}$ 12, Ano 4, série II, outubro 1982]. Pela primeira vez, foi atribuído o Prémio Ferreira da Silva, instituído pela SPQ para "encorajar a qualidade e quantidade de investigação científica em Portugal no domínio da Química em qualquer das suas áreas" [Boletim n. ${ }^{\circ}$ 5, Ano 4, série II, janeiro 1981]. O vencedor da primeira edição do Prémio Ferreira da Silva foi o Prof. Jorge Calado, do IST.

O 8. ${ }^{\circ}$ Encontro decorreu na Universidade do Minho, em Braga, de 9 a 13 de abril de 1985. Contou com 650 participantes, 9 lições plenárias, 32 comunicações convidadas e 209 comunicações em cartaz [Boletim n. ${ }^{\circ}$ 20, série II, junho 1985].

O $10 .^{\circ}$ Encontro decorreu na Universidade do Porto de 6 a 11 de abril de 1987, em simultâneo com as comemorações do $75 .{ }^{\circ}$ Aniversário da SPQ, tendo reunido um total de 561 participantes nacionais e estrangeiros. Contou com 11 lições plenárias, 16 comunicações convidadas e 251 comunicações em painel. [Rev. Port. Quim., Vol. 29, n. ${ }^{0}$ 1-4, 1987].

Os estatutos da SPQ previam também a criação de Divisões temáticas. A primeira foi a Divisão de Educação, que desenvolveu atividade relevante, nomeadamente no âmbito na Delegação Norte, onde foi dinamizada pelos colegas Duarte Costa Pereira e Carlos Corrêa ("Experiências de Salão"). [Cf. Boletins de dezembro 1979, março 1980 e janeiro 1981]. Em 1982 foi criada na Delegação Norte a Divisão de Química Analítica, na sequência de uma proposta para constituir um Grupo de Cromatografia, apresentada por José Luís Figueiredo. A Direção desta Divisão foi entregue a José Luís Figueiredo (FEUP), António Fernando Silva (FCUP) e Alfredo Sá Almeida (UNICER) [Boletim n. ${ }^{\circ}$ 12, Ano 4, série II, outubro 1982]. Esta Divisão promoveu um debate sobre Química Analítica na Indústria no dia 21 de outubro de 1983, integrado nas atividades do 6. ${ }^{\circ}$ Encontro da Sociedade Portuguesa de Química (Aveiro 18-21 de outubro de 1983). As comunicações convidadas então apresentadas, focando três tópicos considerados de grande relevância (automação da análise laboratorial; interação entre o laboratório da empresa e o laboratório exterior; formação profissional no setor da Química Analítica) foram publicadas na Rev. Port. Quím., 25 (n. ${ }^{\circ}$ 3-4), 1983 (páginas 125-137).

Em 14 de janeiro de 1984, foi recebida na Faculdade de Ciências da U. Porto uma delegação do Colégio Oficial de Químicos da Galiza/Associação Nacional de Químicos de Espanha (Delegação da Galiza), com o intuito de promover o intercâmbio científico e técnico com a SPQ. Estiveram presentes nesta $1 .^{a}$ reunião, entre outros colegas, Pelayo Rubido Muñiz, Juan Vieites Baptista de Sousa e José Maria Varela Cardama, por parte do Colégio; e Manuel A.V. Ribeiro da Silva, José Luís Costa Lima, Duarte Costa Pereira e José Luís Figueiredo pela Delegação Norte da SPQ. 
Em 18 de fevereiro realizou-se uma segunda reunião na sede do Colégio Oficial de Químicos da Galiza, em Vigo. Em resultado destes contactos, foi decidido organizar anualmente um Encontro temático, alternadamente na Galiza e na Região Norte. Note-se que estes eventos foram inseridos inicialmente nas atividades da Divisão de Química Analítica, conforme notícia publicada na Rev. Port. Quím., 26 (n. $\left.{ }^{\circ} 1\right) 1984$.

O 1. ${ }^{\circ}$ Encontro Galego-Português de Química realizou-se em Santiago de Compostela, de 14 a 16 de novembro de 1985, sobre o tema “Águas naturais e residuais”. O êxito deste primeiro Encontro, traduzido numa participação muito significativa e entusiástica de químicos da Galiza e do Norte de Portugal, confirmou a pertinência da decisão tomada e justificou amplamente a continuação deste evento.

Entretanto, foram aprovados novos Estatutos da SPQ em janeiro de 1992. Foram criadas Delegações em Aveiro e Braga, além das Delegações do Porto, Coimbra e Lisboa, que sucederam às três anteriormente existentes (Norte, Centro e Sul). As Delegações perderam a sua autonomia financeira, uma vez que as quotas dos associados passaram a ser recebidas diretamente na Sede da SPQ. Em julho de 1992, José Luís Figueiredo foi eleito Presidente da Delegação do Porto [Boletim n. ${ }^{\circ}$ 47, 1992], e manteve-se nesta função até 2007, ano em que foi eleito Presidente da SPQ [Boletim n. ${ }^{\circ}$ 104, março 2007].

Após alguns contactos em 1992, a Delegação do Porto colaborou com a Associação Industrial Portuense (AIP) aquando da realização da QUIMITEC'94 - 1. a feira de Química Aplicada, do Plástico e da Borracha, tendo organizado uma série de palestras no âmbito da Feira, bem como uma demonstração de software educativo de Química no stand da SPQ. Na sequência destas atividades, a Delegação do Porto promoveu a celebração de um Protocolo de Coo- peração entre a Associação Industrial Portuense (AIP) e a SPQ, tendo como objetivo a realização de exposições periódicas no âmbito da Indústria Química, que foi assinado em 1995. Em consequência, a SPQ (Delegação do Porto) apoiou a realização da QUIMITEC'96, que decorreu de 27 a 30 de novembro de 1996, em simultâneo com o $10 .^{\circ}$ Encontro Luso-Galego de Química. Este Protocolo permitiu que os Encontros Luso-Galegos de Química de 1996 e de 1998 fossem realizados na Exponor - Feira Internacional do Porto, em Leça da Palmeira, em condições muito vantajosas. A colaboração com a AIP mereceu a atribuição de um Diploma de Prestígio, entregue à SPQ em 10 de maio de 1997, por ocasião do $10{ }^{\circ}$ aniversário da Exponor [Boletim n. ${ }^{\circ}$ 67, dezembro 1997].

Os Encontros Luso-Galegos de Química realizaram-se ininterruptamente desde 1985 até 2001, tendo passado a encontros generalistas de Química (em vez de Encontros temáticos) a partir de 1996. Estes Encontros constituíram um exemplo ímpar de colaboração entre os químicos da Galiza e do Norte de Portugal, e foram uma marca distintiva das atividades da Delegação do Porto da SPQ. Uma listagem dos primeiros 15 Encontros Luso-Galegos foi publicada no Boletim da SPQ n. 87 (2002) 16-17, juntamente com uma nota explicativa dos motivos que então levaram a Delegação do Porto a suspender esta atividade. Em dezembro de 2004 deram-se os primeiros passos para normalizar as relações com o Colégio de Químicos da Galiza, no decurso de uma reunião com o Decano José António Rodríguez Vázquez (Catedrático da Universidade de Vigo, que em 1984 tinha sido o mentor da colaboração Galego-Portuguesa). No entanto, a decisão de reiniciar a organização dos Encontros Luso-Galegos de Química só foi tomada em abril de 2009, após reunião no Porto com a Direção do Colégio de Químicos da Galiza, liderada pelo Decano António Macho Senra.

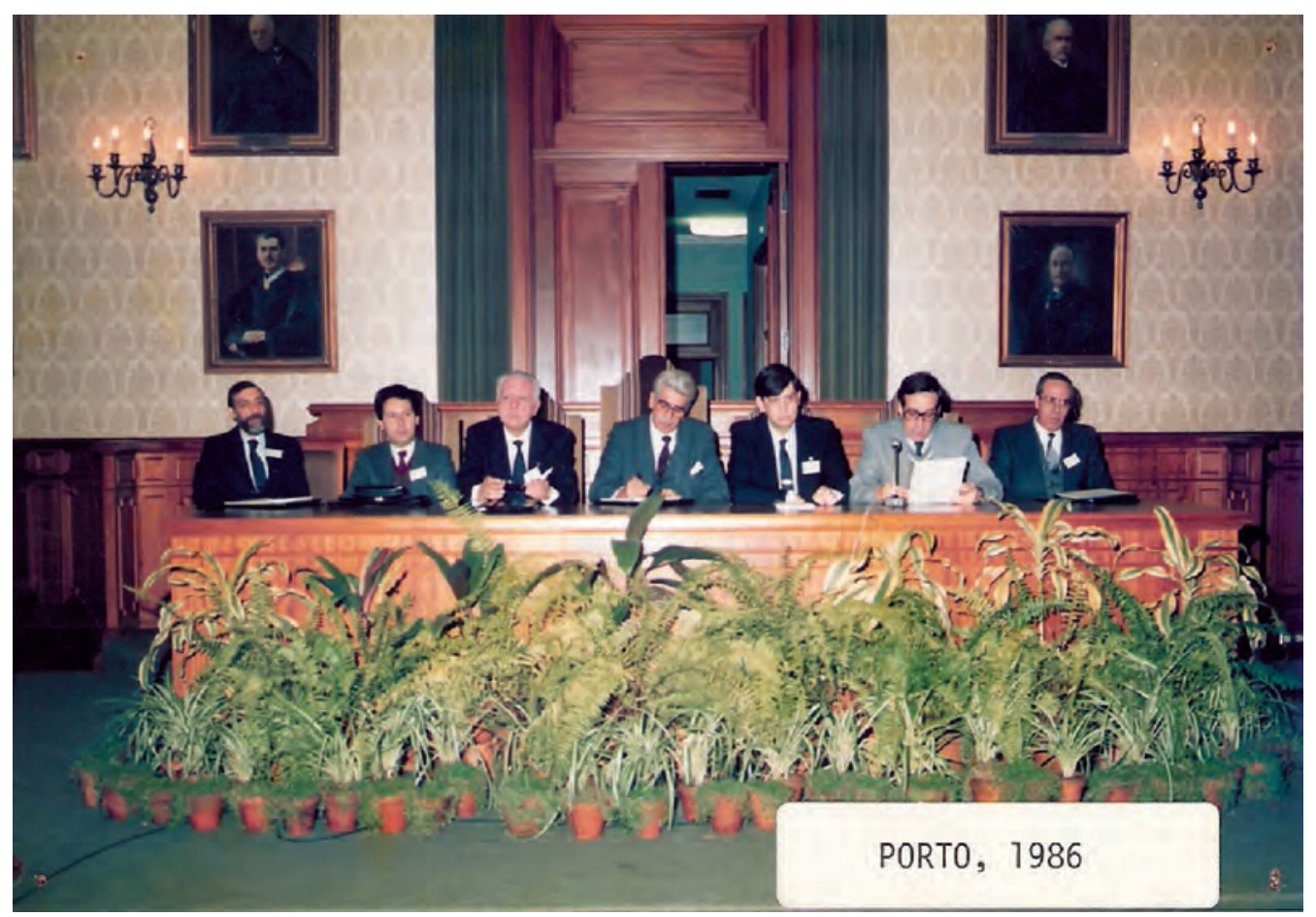

Figura 1 - Sessão inaugural do $2 .^{\circ}$ Encontro Luso-Galego de Química na FCUP (20 de novembro de 1986). Da esquerda para a direita: José Luís Costa Lima, José Luís Figueiredo, José Luís Negro (Presidente da ANQUE), Francisco Carvalho Guerra (Vice-Reitor da UP), Juan Vieites Baptista de Sousa (Colégio Oficial de Químicos de Galicia), Manuel Ribeiro da Silva (Presidente da SPQ e da Delegação Norte), Alberto Roque da Silva. 
Cabe aqui recordar o nome dos colegas da Delegação do Porto que ao longo destes anos estiveram envolvidos na organização (i.e., na Comissão Diretiva) dos Encontros Luso-Galegos de Química: José Luís Costa Lima, Manuel A.V. Ribeiro da Silva, José Luís Figueiredo, Alberto Roque da Silva, Aquiles Barros, Baltazar de Castro e Joaquim Faria.

A Delegação do Porto voltou a assumir a organização do Encontro Nacional de Química em 1996. O XV Encontro (22 a 25 de maio) decorreu no Seminário de Vilar, no Porto, onde se reuniram 589 participantes. O Programa do Encontro incluiu 5 lições plenárias, 15 comunicações convidadas, 4 comunicações orais e 255 comunicações em painel. Incluiu também um debate sobre Química e Ensino com 4 comunicações convidadas, e 12 Sessões Didáticas sobre técnicas e equipamentos, a cargo das empresas patrocinadoras do Encontro.

Em 1991 foi criada a Divisão de Catálise da SPQ, dinamizada a partir da Delegação do Porto, que também se encarregou de organizar o $5^{\circ}$ Encontro (Leiria, 18 e 19 de maio 2001). A partir de 2002, esta Divisão passou a designar-se por "Divisão de Catálise e Materiais Porosos" (DCMP). O perfil da DCMP foi recentemente publicado na revista ChemCatChem 9 (2017) 902-903 (DOI: 10.1002/ cctc.201700268).

Aquando da realização do XV Simpósio Ibero-americano de Catálise (Córdoba, Argentina, setembro de 1996), a Divisão de Catálise e a Delegação do Porto da SPQ apresentaram uma candidatura para organizar o Simpósio do ano 2000, que foi aprovada.

O Simpósio Ibero-americano de Catálise tem vindo a realizar-se bienalmente desde 1968, e constitui o principal fórum de encontro e debate de cientistas e investigadores dos países Ibero-americanos no domínio da Catálise. Já se tinha realizado em Portugal por duas vezes, em 1976 (V
Simpósio, Lisboa, 25-30 de julho) e em 1984 (IX Simpósio, Lisboa, 16-21 de julho). O XVII Simpósio Ibero-americano de Catálise decorreu no Seminário de Vilar, no Porto, de 16 a 21 de julho 2000, e foi pela primeira vez organizado sob a égide da Federação Ibero-americana das Sociedades de Catálise (FISOCAT), e também pela primeira vez no âmbito da SPQ, tendo sido um dos eventos mais mediáticos jamais organizados pela Delegação do Porto. O Programa contou com 4 lições plenárias, 6 comunicações convidadas, e 407 trabalhos científicos (comunicações orais e em painel). Estiveram presentes 318 participantes, além dos membros das Comissões e convidados. Refira-se, a propósito, que o Congresso Ibero-americano de Catálise (designação adotada a partir de 2010) regressa a Portugal em setembro de 2018 para a sua 26. ${ }^{\text {a }}$ edição, no ano em que se celebra o seu $50 .^{\circ}$ aniversário.

Em 2004, a Delegação do Porto organizou a XXIX Reunião Ibérica de Adsorção, que decorreu nas instalações da Faculdade de Ciências da UP de 15 a 17 de setembro tendo reunido 88 participantes [Boletim n. ${ }^{\circ}$ 95, dezembro 2014]. O Programa incluiu 2 Plenárias, 24 comunicações orais e 68 comunicações em painel. O historial deste evento remonta ao ano de 1976, em que se celebrou a "I Reunión Nacional de los Grupos de Trabajo Relacionados com la Investigación en el Campo de la Adsorción”, na Universidade de Granada. Na III Reunión, celebrada em Oviedo em 1978, participou já uma numerosa delegação portuguesa, o que motivou a posterior mudança de nome para "Reunião Ibérica de Adsorção”. Celebraram-se em Portugal a V Reunião (Lisboa, 1980), a X (Porto, 1985), a XVIII (Lisboa, 1993), a XXIII (Évora, 1998), a XXIX (Porto, 2004), a XXXV (Lisboa, 2010) e a 40. ${ }^{\text { }}$ (Évora, 2016).

Ainda em 2004, foi aprovada pela UE a rede europeia de Catálise Aplicada (“ACENET” ERA-Net) em que a Fundação para a Ciência e a Tecnologia (FCT) participou,

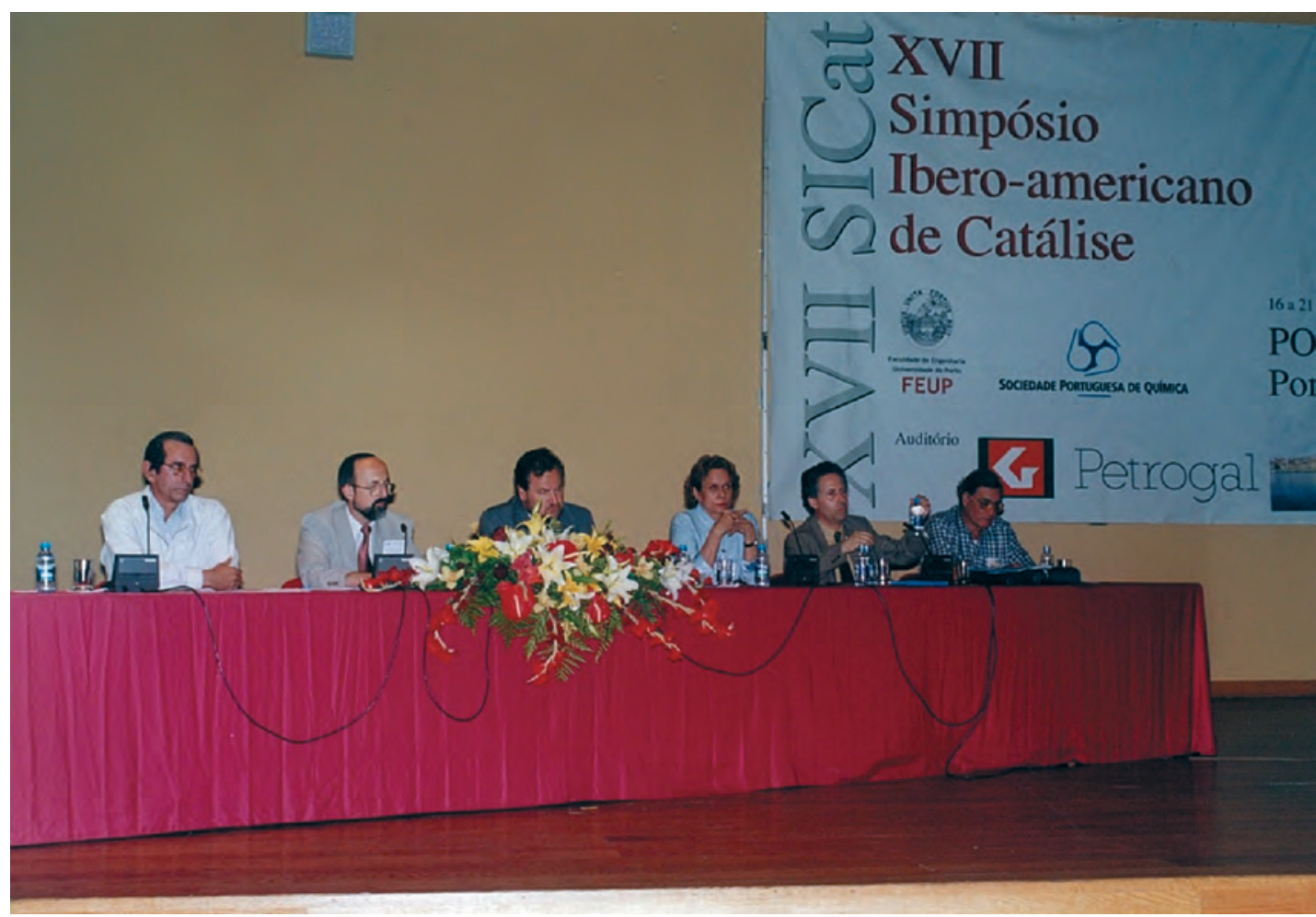

Figura 2 - Mesa da Assembleia Geral da FISOCAT, que decorreu durante o XVII Simpósio Ibero-americano de Catálise, Porto, 20 de julho de 2000. 


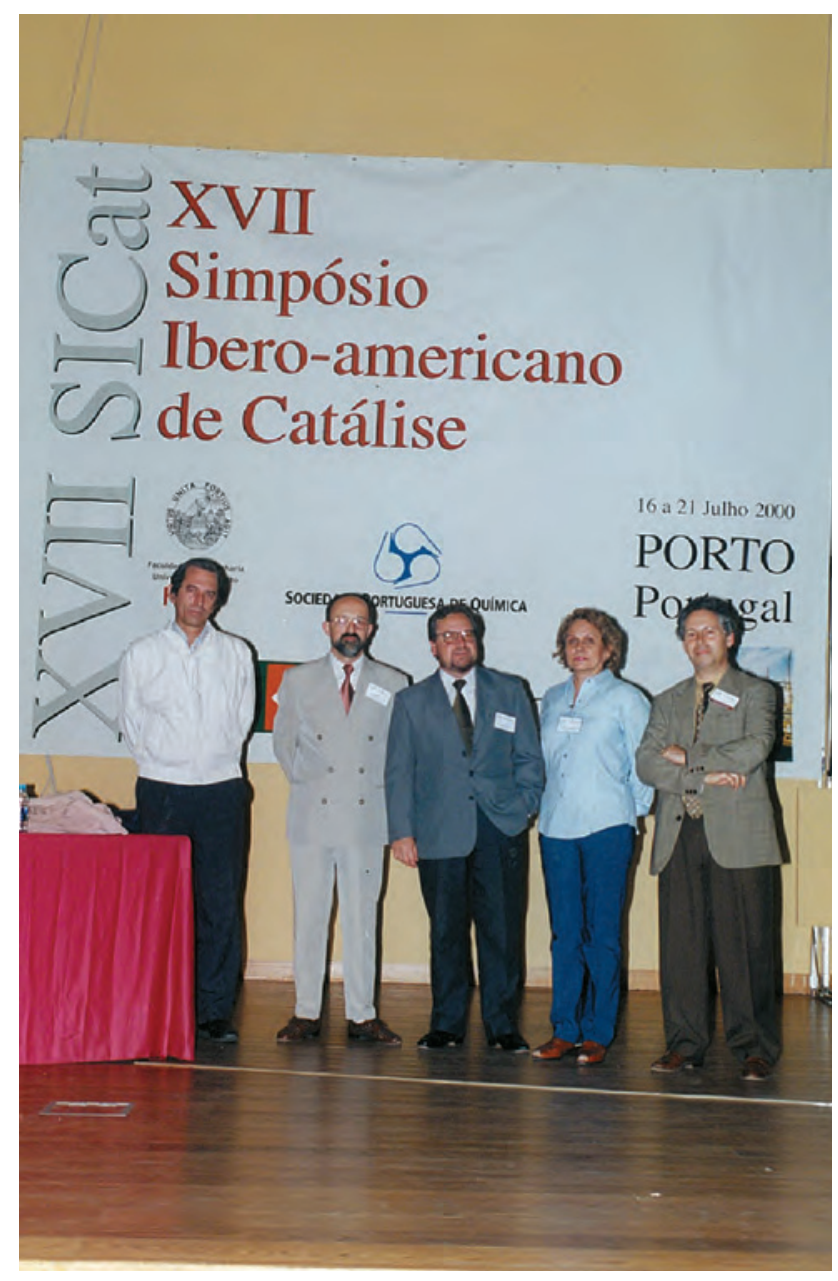

Figura 3 - Comité Executivo da FISOCAT, ano 2000. Da esquerda para a direita: Dilson Cardoso (Brasil), Vicente Cortés (Espanha), Carlos Apesteguia (Argentina), Mireya Goldwasser (Venezuela) e José Luís Figueiredo (Portugal)

juntamente com outros organismos responsáveis pelo financiamento da investigação em nove países europeus (Holanda, Alemanha, França, Polónia, Portugal, Itália, Grécia, Espanha e Reino Unido). José Luís Figueiredo foi o delegado da FCT no Conselho Executivo desta ERA-Net. O 1. ${ }^{\circ}$ Curso Integrado de Catálise, organizado em 2006 pela Divisão de Catálise e Materiais Porosos e pela Delegação do Porto da SPQ, em colaboração com as Universidades de Coimbra, Porto, Aveiro, Lisboa (UTL e UNL) e Évora, e quatro empresas industriais (CIRES, GALP Energia, Quimigal, Hovione), foi estruturado de acordo com as diretrizes propostas pela ACENET no sentido de oferecer aos alunos de pós-graduação e doutoramento um programa de ensino abrangente no domínio da Catálise Aplicada. O Curso foi implementado segundo o modelo alemão: os alunos inscritos reuniam-se com os docentes do Curso num mesmo local (neste caso, no Departamento de Química da Universidade de Coimbra) todas as sextas-feiras durante várias semanas, onde recebiam formação abrangendo as várias vertentes da Catálise: heterogénea, homogénea, enzimática, fotocatálise e electrocatálise. Três sessões, dedicadas aos métodos de caracterização e ensaio de catalisadores, decorreram em Aveiro (Departamento de Química), Porto (CEMUP) e Lisboa (IST). No final foi realizado um Simpósio no IST, para o qual foram convidados vários cientistas estrangeiros. O Curso, que decorreu de 21 de abril a 30 de junho de 2006 e foi frequentado por 50 alunos provenientes de várias Universidades e Institutos Politécnicos, constituiu um enorme êxito, e foi uma das atividades mais gratificantes realizadas (e parcialmente financiada) pela Delegação do Porto da SPQ [Boletim n. ${ }^{\circ}$ 101, junho 2006]. As lições do Curso foram posteriormente coligidas e publicadas em livro ["Catalysis from theory to application”, J.L. Figueiredo, M.M. Pereira, J. Faria (eds.) Coimbra University Press, 2008].

De janeiro de 2007 a janeiro de 2010, a Presidência da Delegação do Porto foi assumida por Joaquim Luís Faria (Vogais: Manuel Fernando Pereira, FEUP e João Paiva, FCUP).

Em 2007 foi estabelecido um acordo com a FEUP em que esta era a morada oficial da Delegação do Porto, e em 2009 foi estabelecido outro protocolo com a Biblioteca da FEUP para a guarda das revistas em papel da ChemPubSoc atribuídas à Delegação do Porto: EurJOC, EurJIC, Chemistry - A European Journal, Chemistry - An Asian Journal, ChemBioChem, ChemMedChem, ChemCatChem e ChemPhysChem.

A Delegação do Porto foi novamente encarregada de organizar o Encontro Nacional de Química em 2008. O XXI Encontro, dedicado à "Química e Inovação”, decorreu nas instalações da FEUP de 11 a 13 de junho, e congregou 380 participantes. Além das lições correspondentes ao Prémio Ferreira da Silva e Medalha Vicente Seabra, o Programa incluiu 4 lições plenárias, 22 comunicações convidadas, 22 comunicações orais e 240 comunicações em painel, além de 3 workshops e um debate, vocacionados para o ensino da Química nas Escolas. Durante este Encontro foi assinado um Protocolo de Cooperação entre a SPQ e a RSEQ (Real Sociedad Española de Quimica), que em particular instituiu um prémio anual (Prémio Luso-Espanhol de Química), que posteriormente recebeu a designação de Conferência Lourenço-Madinaveitia, para recordar dois químicos notáveis: Agostinho Vicente Lourenço (1822-1893) e Antonio San Quintín Madinaveitia y Tabuyo (1890-1974).

A Presidência da Delegação do Porto foi assumida por José Luís Costa Lima (Vogais: Joaquim Luís Faria, FEUP e Baltazar Castro, FCUP) de janeiro de 2010 a novembro de 2013, e no triénio seguinte foi novamente assumida por Joaquim Luís Faria (Vogais: Paula Andrade FFUP, Pedro Fernandes, FCUP).

Tendo sido reatadas em 2009 as relações entre a Delegação do Porto e o Colégio de Químicos da Galiza, retomou-se a organização dos Encontros Luso-Galegos de Química. O 16. ${ }^{\circ}$ Encontro decorreu na Universidade de Aveiro de 10 a 12 de novembro de 2010, e desde então este evento tem vindo a realizar-se anualmente (Pontevedra, 2011; Vila Real, 2012; Vigo, 2013; Porto, 2014; Pontevedra 2015; Bragança, 2016). Em novembro de 2017 terá lugar o $23 .^{\circ}$ Encontro, no Ferrol.

Em 2011, a Delegação do Porto colaborou no programa de eventos dedicados ao Ano Internacional da Química [Boletim n. ${ }^{\circ}$ 123, dezembro 2011]. Além disso, desde esse ano tem participado ativamente em outras iniciativas, como por exemplo a "Noite dos Investigadores."

Em 2012, sob os auspícios da Delegação do Porto, realizou-se um dos mais importantes congressos em quí- 
mica solar e fotocatálise, o 7th European Meeting on Solar Chemistry and Photocatalysis: Environmental Applications. Não foi por acaso que três das mais relevantes revistas internacionais de ciência (Catalysis Today, Chemical Engineering Journal e Photochemical \& Photobiological Sciences) aceitaram incluir no seu plano de publicações contribuições selecionadas deste congresso. Foi um evento de 4 dias realizado no requintado Hotel Ipanema Park, no Porto, com um programa científico e social ao melhor nível, que ainda hoje é uma referência e perdura na memória de todos os que nele participaram.

Desde 2013 que as Olimpíadas de Química Jr. passaram a realizar-se também na FEUP (além da tradicional realização na FCUP) e a ser apoiadas mais ativamente pela Delegação do Porto, permitindo mais que duplicar o número de escolas participantes. Foi também dada maior atenção a realizações estudantis no âmbito da Universidade do Porto, nomeadamente as Jornadas do Departamento de Engenharia Química realizadas pelo Núcleo de Estudantes de Engenharia Química (NEEQ).

Em 2015, um grupo de sócios da SPQ propôs a criação do Grupo do Carbono, que foi aprovado pela Direção Nacional. Desde então, a Delegação do Porto tem vindo a dinamizar as atividades do Grupo, e vai organizar a $1 .{ }^{a}$ Reunião do Grupo do Carbono no Porto, nos dias 12 e 13 de junho de 2017 (http://1rgc.eventos.chemistry.pt/).
Em dezembro de 2016 foi eleito para a Presidência da Delegação do Porto o colega Victor Freitas, da FCUP (Vogais: Adrián Silva, FEUP e Alberto Araújo, FFUP).

Ao longo dos últimos 40 anos, a Delegação do Porto da SPQ manteve uma atividade intensa e continuada, tendo sido responsável pela criação e dinamização das Divisões de Química Analítica e de Catálise, e mais recentemente, do Grupo do Carbono; pela organização de numerosos eventos científicos, com destaque para os Encontros Luso-Galegos de Química (1985-2017), para o XVII Simpósio Ibero-americano de Catálise (2000), para o Curso Integrado de Catálise (2006) e para o 7th European Meeting on Solar Chemistry and Photocatalysis: Environmental Applications (2012); e participando em diversas outras atividades da SPQ, nomeadamente na Divisão de Educação e nas Olimpíadas da Química. Tudo isto só foi possível graças à dedicada colaboração de um (relativamente pequeno) grupo de sócios que deram o melhor do seu esforço em prol da SPQ, e da Química em geral.

José Luís Figueiredo

Nota do editor: O texto original do autor foi convertido para a grafia do Acordo Ortográfico da Língua Portuguesa de 1990, em estrito cumprimento das normas editoriais do QUÍMICA.

Atualidades Científicas

\section{Heptaceno isolado e caracterizado}

Os hidrocarbonetos aromáticos policíclicos contendo um arranjo retilíneo de anéis de benzeno fundidos constituem uma classe de compostos com um papel importante na área da eletrónica molecular. Em particular, o tetraceno, o pentaceno e seus derivados têm sido usados com sucesso em dispositivos fotovoltaicos, OLEDs e transístores. No entanto, moléculas maiores que o pentaceno são difíceis de manipular devido à sua instabilidade e baixa solubilidade. De facto, apenas a série de moléculas até ao hexaceno foram isoladas puras no estado sólido.

O heptaceno manteve-se elusivo até à obtenção de provas inequívocas da sua existência num artigo publicado por Mondal et al. em 2006 em que conseguiram sintetizar e estabilizar a molécula durante algumas horas numa matriz de PMMA. Recentemente, uma equipa de investigadores alemães e americanos mostrou que o heptaceno pode ser obtido através da reação de clivagem do seu dímero no estado sólido a temperaturas elevadas. A monitorização por RMN de ${ }^{13} \mathrm{C}$ no estado sólido mostrou que o heptaceno sofre uma reação de ciclodimerização originando lentamente o seu dímero. No entanto, o seu tempo de meia-vida é de várias semanas à temperatura ambiente. Foi possível ainda demonstrar a possibilidade de obtenção de filmes finos de heptaceno por deposição de vapor.

\section{Fontes:}

Molecular Tweezers for $\mathrm{C}_{60}$, http://www.chemistryviews.org/details/news/10015341/Molecular_Tweezers_for_C60.html (Acedido em 10/11/2016)

G. Bastien, P. I. Dron, M. Vincent, D. Canevet, M. Allain, S. Goeb, M. Sallé. $\mathbf{C}_{60}$ Recognition from Extended Tetrathiafulvalene Bis-acetylide Platinum(II) Complexes. Org. Lett. 18 (2016) 5856-5859. DOI: 10.1021/acs. orglett.6b02915

Paulo Mendes (pjgm@uevora.pt)
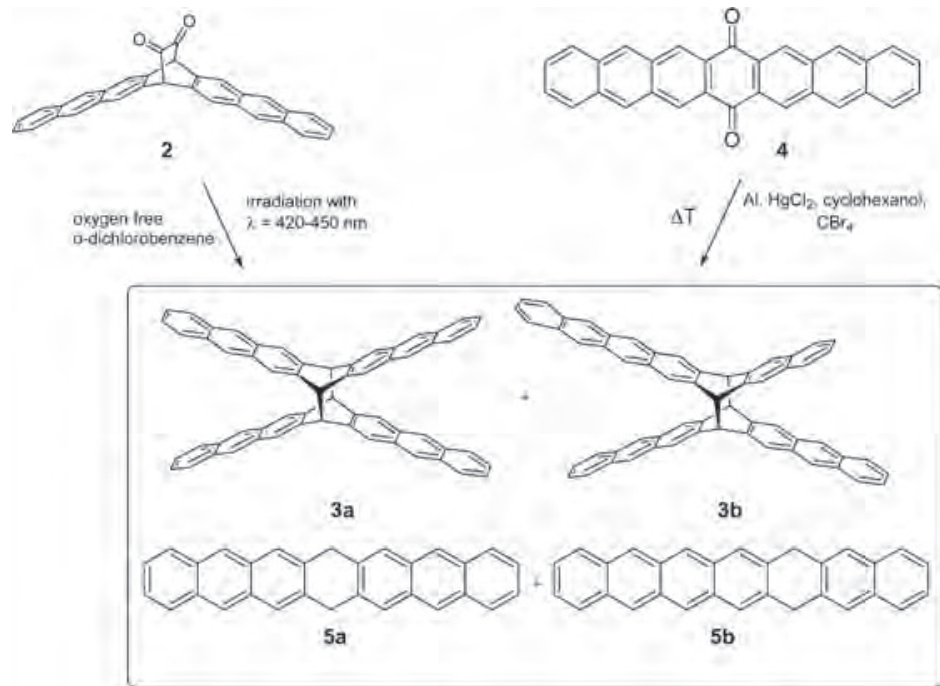